\title{
Audiobooks as a window to the world
}

\author{
Maria Cahill, Ph.D. \\ University of Kentucky \\ School of Library and Information Science \\ 355 Little Library Building \\ Lexington, KY 40506 \\ United States of America \\ maria.cahill@uky.edu \\ Jennifer Richey, Ph.D. \\ Texas Woman's University \\ School of Library \& Information Studies \\ Stoddard Hall, Room 404 \\ P.O. Box 425438 \\ Denton, TX 76204-5438 \\ United States of America \\ Jrichey1@twu.edu
}

\begin{abstract}
Library, literacy, and children's literature professionals promote the benefits of transacting with audiobooks, and awards are bestowed upon audiobooks worldwide. Research spanning decades and conducted worldwide has explored the use of audiobooks for promoting literacy skill development. These studies have explored various uses of audiobooks and report mixed results for different types of readers and for readers of varying levels of proficiency. Yet, huge gaps exist in the research with many aspects of audiobook use still uninvestigated. This paper reports the disconnect between professionals' claims regarding the benefits of audiobooks for children and those verified by empirical studies. It identifies the gaps in the scholarship surrounding audiobooks and calls attention to those areas in which audiobooks have potential to support children's interests and needs.
\end{abstract}

Keywords: Audiobooks, Reading research

\section{Claims about audiobook benefits}

Many educators and literacy proponents advocate audiobook use for literacy development purposes (Grover \& Hannegan, 2012). Articles touting the benefits of audio text use with children of various ages are found in numerous education publications, and children's and teen librarians have also endorsed the use of audiobooks with children of all ages.

Advocates of audiobooks have lauded the format for its role in:

- Motivating reading (Chen, 2004; Maughan, 2004; Neuman, 2005; Rickelman \& Henk, 1990; Serafini, 2006);

- Increasing literary appreciation; (Rickelman and Henk, 1990); 
- Encouraging children to explore new titles and genres (Serafini, 2006);

- Piquing children's interests (Varley, 2002);

- Enhancing literacy engagement (Clark, 2007);

- Developing children's language (Neuman, 2005; Wolfson, 2008);

- Improving reading fluency (Chen, 2004; Neuman, 2005; Serafini, 2006);

- Promoting listening skills (Burkey, 2009; Clark, 2007; Neuman, 2005; Varley, 2002);

- Helping struggling readers connect sounds to text; (Serafini, 2006);

- Supporting multiculturalism (Yokota \& Martinez, 2004);

- Instigating critical thinking (Clark, 2007);

- Introducing children to high quality literature (Ferreri, 2000; Maughan, 2004; Serafini, 2006);

- Supporting English language learners in their acquisition of English (Chen, 2004; Skouge, Rao, \& Boisvert, 2007);

- Promoting discussion (Varley, 2002);

- Developing children's vocabularies (Chen, 2004; Maughan, 2004; Rickelman \& Henk, 1990; Serafini, 2006; Varley, 2002; Wolfson, 2008);

- Improving general reading skills (Ferreri, 2000); and

- Facilitating comprehension (Chen, 2004; Rickelman \& Henk, 1990; Serafini, 2006; Wolfson, 2008).

Some of the benefits attributed to audiobooks have been investigated by researchers, others are extrapolations from studies of reading in other contexts that have subsequently been ascribed to audiobooks, and some are anecdotal in nature.

\section{Contributions of audiobooks as reported by research}

\section{Fluency}

Audiobooks can be used in a reading-while-listening (RWL) which calls on the reader to listen to an audio recording of a text while following along with the printed version in one of the following manners: either reading along silently, subvocalizing, or orally reading. Many studies have examined the effect of RWL on fluency development. This method has been used successfully with English language learners (Blum, Koskinen, Tennant, Parker, Straub, and Curry, 1995) with maintained improvements in general oral fluency beyond the intervention period (Kupzyk, McCurdy, Hofstadter, and Berger, 2011).

Similarly, the method has been viable for young struggling readers (Gilbert, Williams, and McLaughlin, 1996) as well as pre-adolescents (van der Leij, 1981). The overall conclusions of these studies is that RWL is as effective as other methods for improving reading rates and accuracy for struggling readers and that it is more efficient than some. Hollingsworth (1970) examined the effectiveness of a RWL technique for fourth grade students without reading difficulties and found no significant differences in performance on speed or accuracy compared to students in a control group.

All of the studies reported above used researcher-developed audio recordings. Carbo (1978) found that her students could not adequately follow along with commercially produced audiobooks because the reading rates were too fast. Yet, several studies have investigated 
the impact of commercially produced recordings on students' fluency development. Elementary students with reading disabilities in the U.S. used digitally downloaded audiobooks on MP3 players daily for eight weeks during Sustained Silent Reading. The students showed significant gains in words correct per minute compared with a control group. Similarly, elementary students in Edinburgh, Scotland used commercially produced fiction audiobooks during English language arts study. Though these students made gains in accuracy and rate, the differences were not significantly different from students who had engaged in silent reading nor those who had continued with regular instruction (Bircham, Shaw, and Robertson, 1997). Finally, four African American students in a fourth grade classroom in the US participated in a study the compared repeated reading with RWL. Students listened to the publisher produced audio edition of the instructional materials. Both interventions resulted in increased fluency and increased comprehension rates for all students. One of the students performed better in the repeated reading condition, but the RWL condition resulted in more time spent reading for three of the students.

\section{Word reading}

Two of the studies that investigated the impacts of RWL on fluency also examined its effect on isolated word reading. In one of the studies, participants were students who struggled with reading, while students in the other study represented average readers. Twenty reading disabled children in the Netherlands were matched and divided into listen-while reading or control groups for four sessions over two weeks. Of the lowest performing children, those in the listen-while-reading condition made better gains in reading a list of words that were contained in the books In this same classroom a small group engaged in RWL over 8 weeks. Compared to a control group, these children also showed improvements in reading words in isolation. (van der Leij, 1981). Seventy-two children ranging in age 6.8 to 7.5 years, with an average of 7.2 years were assigned to one of four conditions: guided reading, RWL, speechselect (in which touch technology enabled students to hear selected words at the point of need), and control. Students in the guided reading and speech-select conditions had significant increases in word recognition compared to RWL and control conditions. The researchers concluded that "only when beginning readers are engaged in efforts to read on their own as much as possible can gains in reading skill be expected (Reitsma, 1998, pp. 233-234)."

\section{Reading comprehension}

As with research investigating other components of reading, studies exploring the effects of audio delivery on reading comprehension primarily employ researcher-created audio recordings. In fact, only one study (Abelson and Peterson, 1983) used commercially produced audiobooks, and only half of the recordings used in the study were commercially produced. This study found no differences in comprehension for male struggling readers in grades 4 through 6 across three listening conditions: RWL with a recorded book, listening only to recorded book, and RWL with a live reader. In studies described previously (Hollingsworth, 1970; Lionetti, and Cole, 2004) no significant differences in reading comprehension were noted for typical fourth graders engaging in RWL nor for struggling 4th and 5th grade boys at either RWL rate.

Other research shows variable effects of auditory delivery for advancing reading comprehension. In the study described previously (Hawkins, Marsicano, Schmitt, \& 
McCallum, 2015) in which fourth grade students engaged in repeated reading and RWL conditions, both interventions resulted in increased comprehension rates for all students, though one of the students performed better in the repeated reading condition. Across three weeks, thirteen above grade level readers in grades one through five engaged in reading and RWL essays at varied reading levels Five of the students performed better on comprehension measures in the RWL condition, 4 in the read only condition, and 4 showed no differences (Simkins, 2004).

Finally, other studies demonstrate the benefits of RWL on reading comprehension. In a study that investigated the efficacy of round robin reading, in which students take turns reading aloud, RWL, and silent reading, researchers found that students' comprehension was best under the listening condition (Lynch, 1988). Similarly, Shany and Biemiller (1995) found significant advantages in reading comprehension for 3rd and 4th grade students receiving teacher assistance and RWL compared to controls; however, they also found that RWL led to more actual reading and greater gains in listening comprehension than teacher assistance.

\section{Reading Comprehension strategies}

Researchers in the Netherlands tested the efficacy of teaching reading comprehension strategies in the listening context. Students in experimental conditions were trained to apply the four reciprocal teaching strategies (clarifying, questioning, summarizing, and predicting) using auditorily presented texts; while, students in control conditions received normal classroom reading comprehension instruction. Experimental and control groups exhibited significant differences in ability to use strategies but not in general reading comprehension nor listening comprehension.

\section{Vocabulary}

Only one study formally (Hollingsworth, 1970) assessed vocabulary growth as a result of RWL interactions and no significant growth was detected. Wellner (2010) explored the effects of an audiobook home reading program on the book interactions of three limited English proficiency kindergarten students in the United States. The children's parents reported that the audiobooks helped their children learn English and English pronunciations. A middle school teacher with a large portion of English language learners reported action research which demonstrated improvement in the quality of students' writing journal entries in terms of vocabulary used, and quality of writing (Patten and Craig, 2007).

\section{Reading Motivation}

Though reading motivation is frequently discussed as a beneficial consequence of engagement with audiobooks, only one study (Esteves \& Whitten, 2011) formally assessed it, and no difference in reading attitude (measured with Elementary Reading Attitude Survey-McKenna \& Kear, 1990) between students in an a control group and those who engaged in RWL with commercially produced audiobooks. Nevertheless, changes in students' attitudes are conveyed through posture (Carbo, 1978), appearance (Boeglin, \& Donovan, 2013), willingness to engage with them again (Whittingham, Huffman, Christensen, \& McAllister, 2013), and teacher reports (Koskinen, Blum, Bisson, Phillips, Creamer, and Baker, 2000). While two of the three kindergarteners in an audiobook home program reported that they enjoyed listening to the books, they indicated that they would rather have 
their parents read books to them (Wellner, 2010). In a study which measured the effects of an online audiobook program in Hong Kong, the majority of students reported enjoying use of the database but nearly a third did not, and over half expressed a preference for stories to be told by a live person (Lo, 2009).

\section{Discussion}

Audiobook proponents confer many benefits upon the medium, yet few studies have examined the use of audiobooks beyond a RWL approach. Regardless of validation through research, many librarians have witnessed first-hand the joys of children transacting with audiobooks, and they should continue to encourage children to use this medium as a form of entertainment. As we did in a previous analysis of audiobook research (Cahill \& Richey, 2013), we echo the sentiments of other researchers (e.g. Moran, Ferdig, Pearson, Wardrop, \& Blomeyer, 2008): more studies investigating audiobooks and other technologies are necessary for truly understanding the nuanced contributions of audiobooks to children's literacy development and proficiencies.

\section{References}

Abelson, A. G., \& Petersen, M. (1983). Efficacy of "Talking Books" for a group of reading disabled boys. Perceptual and Motor Skills, 57, 567-570.

Bircham, A., Shaw, M. \& Robertson, A. (1997). Enhancing reading development using audiotaped books. Educational Psychology in Practice, 13(3), 181-187.

Blum, I. H., Koskinen, P. S., Tennant, N., Parker, E. M., Straub, M., \& Curry, C. 1995). Using audiotaped books to extend classroom literacy instruction into the homes of second-language learners. Journal of Reading Behavior, 27(4), 535-563.

Boeglin, B., \& Donovan, L. (2013). Storytime using iPods: Using technology to reach all learners. TechTrends, 57(6), 49-56.

Burkey, M. (2009). Long-form listening. Book Links, 18(6), 26-27.

Cahill, M., \& Richey, J. (2014). Do you hear what I hear? Questioning the legitimacy of audiobooks as "reading" material. Paper presented at International Federation of Library Associations. Paris, France. Retrieved from http://www.reseaucanope.fr/ifla-seminairebnf/pdf/cahill article.pdf

Carbo, M. (1978). Teaching reading with talking books. Reading Teacher 32(3), 267-73.

Chen, S, L. (2004). Improving reading skills through audiobooks. School Library Media Activities Monthly, 21(1), 22-25.

Clark, R. (2007). Audiobooks for children: Is this really reading? Children and Libraries, 5(1), 49-50.

Esteves, K. J., Whitten, E. (2011). Assisted reading with digital audiobooks for students with reading disabilities. Reading Horizons, 51(1), 21-40. 
Ferreri, P. (2000). Listening for literacy: A guide for using children's audiobooks. Teaching Pre K-8, 31(2) 61.

Gilbert, L. M., Williams, R. L., \& McLaughlin, T. F. (1996). Use of assisted reading to increase correct reading rates and decrease error rates of students with learning disabilities. Journal of Applied Behavior Analysis, 29, 255-257.

Grover, S., \& Hannegan, L. D. (2012). Listening to learn: Audiobooks supporting literacy. Chicago: American Library Association.

Hawkins, R. O., Marsicano, R., Schmitt, A. J., \& McCallum, E. (2015). Comparing the efficiency of repeated reading and listening-while-reading to improve fluency and comprehension. Education and Treatment of Children, 38(1), 49-70.

Hollingsworth, P. M. (1970). An experiment with the impress method of teaching reading. The Reading Teacher, 24(2), 112-114, 187.

Koskinen, P. S., Blum, I. H., Bisson, S. A., Phillips, S. M., Creamer, T. S., \& Baker, T. K. (2000). Book access, shared reading, and audio models: The effects of supporting the literacy learning of linguistically diverse students in school and at home. Journal of Educational Psychology, 92(1), 23-36.

Kupzyk, S., McCurdy, M., Hofstadter, K. L., \& Berger, L. (2011). Recorded readings: A taped parent-tutoring intervention. Journal of Behavioral Education, 20, 87-102.

Lionetti, T., \& Cole, C. (2004). A comparison of the effects of two rates of listening while reading on oral reading fluency and reading comprehension. Education and Treatment of Children, 27(2), 114-129.

Lynch, D. J. (1988). Reading comprehension under listening, silent, and round robin reading conditions as a function of text difficulty. Reading Improvement, 25, 98-104.

Maughan, S. (2004). Summer listening 101: Audiobooks enhance required reading lists. Publishers Weekly, 251(24), 37.

Neuman, S. B. (2005). Audio books for kids: Add to your child's reading pleasure and learning experience by popping in a book on tape or CD. Scholastic Parent \& Child, 12(4), 22.

Reitsma, P. (1988). Reading practice for beginners: Effects of guided reading, reading-whilelistening, and independent reading with computer-based speech feedback. Reading Research Quarterly, 23(2), 219-235.

Rickelman, R. and Henk, W. (1990). Children's literature and audio/visual technologies. The Reading Teacher, 43(9), 682-684. 
Serafini, F. (2006). Audiobooks \& literacy: An educator's guide to utilizing audiobooks in the classroom. Random House Inc.: Reaching Reluctant Readers. Retrieved from http://www.randomhouse.com/highschool/RHI magazine/pdf/RHI06.pdf

Shany, M. T., \& Biemiller, A. (1995). Assisted reading practice: Effects on performance for poor readers in grades 3 and 4. Reading Research Quarterly, 30(3), 382-395.

Simkins, J. J. (2004). Study in the use of audiobooks for reading in gifted students (unpublished thesis). Wichita, KS: Witchita State University.

Skouge, J. R., Rao, K., \& Boisvert, P. C. (2007). Promoting early literacy for diverse learners using audio and video technology. Early Childhood Education Journal, 35(1), 5-11.

van der Leij, A. (1981). Remediation of reading-disabled children by presenting text simultaneously to eye and ear. Bulletin of the Orton Society, 31, 229-243.

Varley, P. (2002). As good as reading? Kids and the audiobook revolution," The Horn Book Magazine, 78(3), 251-262.

Wellner, M. (2010). How an audiobook library program influences book interactions of three ESL kindergartners (unpublished Master thesis). Hamline University, Saint Paul, MN.

Wolfson, G. (2008). Using audiobooks to meet the needs of adolescent readers. American Secondary Education, 36(2), 105-114.

Yokota, J., \& Martinez, M. (2004). Authentic listening experiences: Multicultural audiobooks. Book Links, 13(3), 30.

\section{Biographical Notes}

Maria Cahill is an Assistant Professor at the University of Kentucky where she holds a joint appointment in the School of Library and Information Science and the Department of Educational Leadership. Her research focuses on the role of libraries in supporting the literacy development of children.

Jennifer Richey has worked as an Assistant Professor at Texas Woman's University's School of Library and Information Studies in Denton, Texas since 2011 where she teaches courses focusing school library certification, young adult literature, and youth library programs. Her primary research interest is on health information literacy of adolescents. Prior to that, she was an elementary school librarian in the Austin, Texas area. 